\title{
Epigenetic function of activation-induced cytidine deaminase and its link to lymphomagenesis
}

\author{
Pilar M. Dominguez ${ }^{1}$ and Rita Shaknovich ${ }^{1,2 *}$ \\ ' Division of Hematology and Oncology, Weill Cornell Medical College, New York, NY, USA \\ ${ }^{2}$ Department of Pathology and Laboratory Medicine, Weill Cornell Medical College, New York, NY, USA
}

\section{Edited by:}

Paolo Casali, University of Texas

School of Medicine, USA

\section{Reviewed by:}

To-Ha Thai, Harvard Medical School, USA

Jayanta Chaudhuri, Memorial Sloan Kettering Cancer Center, USA

*Correspondence:

Rita Shaknovich, Department of Medicine, Weill Cornell Medical College, 1300 York Avenue Building C Room 620C, New York, NY 10065, USA

e-mail: ris9004@med.cornell.edu
Activation-induced cytidine deaminase (AID) is essential for somatic hypermutation and class switch recombination of immunoglobulin (lg) genes during B cell maturation and immune response. Expression of AID is tightly regulated due to its mutagenic and recombinogenic potential, which is known to target not only lg genes, but also non-lg genes, contributing to lymphomagenesis. In recent years, a new epigenetic function of AID and its link to DNA demethylation came to light in several developmental systems. In this review, we summarize existing evidence linking deamination of unmodified and modified cytidine by AID to base-excision repair and mismatch repair machinery resulting in passive or active removal of DNA methylation mark, with the focus on B cell biology. We also discuss potential contribution of AID-dependent DNA hypomethylation to lymphomagenesis.

Keywords: activation-induced cytidine deaminase, DNA methylation, epigenetics, B cells, lymphomagenesis

\section{DYNAMIC NATURE OF METHYLOME DURING B CELL DEVELOPMENT}

Epigenetic mechanisms of regulation including histone modifications, non-coding RNA-mediated gene regulation, chromatin remodeling, and DNA methylation (1) play an important role in $\mathrm{B}$ cell differentiation and the antibody response (2). DNA methylation is essential during $\mathrm{X}$-chromosome inactivation, imprinting, and tissue differentiation $(3,4)$. This epigenetic modification refers to the addition of a methyl group at the $\mathrm{C} 5$ position of cytosine $(\mathrm{C})$, mostly when $\mathrm{C}$ is bound to guanine $(\mathrm{G})$ creating a $\mathrm{CpG}$ site in mammalian organisms $(5,6)$, with less common nonCpG methylation detected in embryonic stem cells (ESCs) and brain tissue $(7,8)$. The addition of the methyl group is catalyzed by the family of DNA methyltransferases (DNMTs) (9), whereas DNA demethylation can be a passive or an active process. Passive demethylation occurs when methylC $(\mathrm{mC})$ mark is not faithfully reproduced either during replication or due to DNA damage, while active demethylation requires the action of enzymes and can be replication-independent $(10,11)$. However, the molecules involved in the 5-methylC $(5 \mathrm{mC})$ active demethylation are still not clearly defined (see below). Several studies have investigated the DNA methylation landscape in B cells and the role of the DNA methylome in B cell development. Ji et al. demonstrated in a mouse model using Comprehensive High-throughput Array-based Relative Methylation analysis (CHARM) (12) that lymphoid commitment requires more DNA methylation than myeloid lineage with

Abbreviations: BCR, B cell receptor; BER, base-excision repair; BL, Burkitt lymphoma; CSR, class switch recombination; DLBCL, diffuse large B cell lymphoma; DNMTs, DNA methyltransferases; DSBs, double strand DNA breaks; EMT, epithelial-mesenchymal transition; ESC, embryonic stem cells; FL, follicular lymphoma; GCBs, germinal center B cells; Ig, immunoglobulin; iPSCs, induced pluripotent stem cells; MMR, mismatch repair; NBs, naïve B cells; PGCs, primordial germ cells; SHM, somatic hypermutation; TLR, toll-like receptor. myeloid skewing of lineages in DNMT1 hypomorphic animals. Loss of methylation predominates during progression of Multipotent Progenitors (MPPs) to Common Lymphoid Progenitors (CLPs) $(13,14)$. During transition from naïve B cells (NBs) to germinal center B cells (GCBs), occurring in the secondary lymphoid organs after $\mathrm{T}$ cell-mediated activation, there is marked demethylation of the genome $(15,16)$. Memory and plasma cells display DNA methylation patterning very similar to GCBs, although the three subpopulations of $\mathrm{B}$ cells differ substantially at the transcriptional level (16). The use of the DNA demethylating agent Decitabine results in complete abrogation of the GCs, while preserving the primary follicles (15), underscoring an important biological role of methylation in B cell development. The fact that entrance of NBs into the GC reaction is characterized by marked upregulation of DNMT1 and simultaneous hypomethylation of many genomic loci suggests yet unknown mechanisms of passive or active demethylation after B cell activation. In this review, we would like to explore the potential role of activation-induced cytidine deaminase (AID) in modifying the methylome of mature B cells. We will present and analyze large amount of conflicting evidence that accumulated up to date linking AID with epigenetic modifications during development and B cell differentiation.

\section{FUNCTION OF AID IN B CELL DEVELOPMENT}

NBs enter the GC reaction and undergo marked changes in transcriptional program, including dramatic upregulation of the enzyme AID (or AICDA), a member of the APOBEC family of cytidine deaminases that is required for both somatic hypermutation (SHM) and class switch recombination (CSR) (17-19). SHM results in the introduction of somatic mutations in the rearranged $\mathrm{V}(\mathrm{D}) \mathrm{J}$ region of the $\mathrm{Ig}$ genes $(\mathrm{IgV})$ in order to generate antibodies with high affinity antigen binding sites $(20,21)$. Additionally, GCBs undergo a process of CSR of the constant 
region of the immunoglobulin ( $\mathrm{Ig}$ ) heavy chain $\left(\mathrm{C}_{\mathrm{H}}\right)$, generating isotypes with different immunological functions but the same antigen-specificity (22-24). Both SHM and CSR are initiated by the deaminase activity of AID, which is able to convert deoxycytosines $(\mathrm{dC})$ into deoxyuracils $(\mathrm{dU})$ in a single-stranded DNA, producing $\mathrm{dU}: \mathrm{dG}$ mismatches that are removed by base-excision repair (BER) and mismatch repair (MMR) pathways $(19,25,26)$. AID can also deaminate $5 \mathrm{mC}$ to thymine $(\mathrm{T})$, although with less efficiency (27). AID is expressed in B cells in a stage specific manner during transition of NB through the GCs (28). NBs integrate signals through B cell receptor (BCR) and Toll-like receptors (TLRs), along with stimulation via surface receptors, such as CD40 and cytokine receptors, to initiate the NF- $\kappa \mathrm{B}$-mediated AID transcription (29). In the secondary lymphoid organs, AID is expressed in a subpopulation of dark and outer zone GCBs and in large extrafollicular B cells, which have evidence of CD40 and BCR stimulation (28), and is downregulated after differentiation of GCBs to memory and/or plasma cells $(30,31)$. In addition, viral infection of B cells can induce expression of AID (31-34). Ig genes are the main targets of AID, with a mutation rate of $10^{-4}$ to $10^{-3} / \mathrm{bp}$ per generation $(35,36)$. Nonetheless, non-Ig genes such as BCL6, CD79A, CD79B, or CD95 are also susceptible to AID-mediated mutations (37-40). Moreover, Liu et al. reported that around 25\% of the highly expressed genes in GCBs, including Bcl6, Cd83, Pim1, Pax5, and Myc among others, experienced AID-mediated deamination and low-level of SHM (41). The authors demonstrated that these non-Ig genes were protected from mutations in normal B cells due to the activity of high-fidelity BER factors. Besides, they observed that there was correlation between target regions of AID and sites of chromosomal translocations and deletions present in human lymphomas (41). They proposed that malfunction of repair machinery could lead to AID-mediated mutations and chromosomal instability, and finally to tumorigenesis. In line with these results, Yamane et al. performed chromatin immunoprecipitation sequencing (CHIPseq) for AID in ex vivo activated B cells and proposed that AID was recruited genome-wide by stalled PolII polymerases, inducing low-level of hypermutation in those AID-targeted genes (42). Importantly, these findings provided insight into the role of AID in lymphomagenesis.

\section{EVIDENCE LINKING AID TO DNA DEMETHYLATION}

There is a body of accumulating evidence linking AID to genomewide epigenetic changes, and specifically to DNA demethylation (43). A significant discovery has been made in recent years that implicated AID in DNA demethylation in three paradigms: epigenetic reprogramming in heterokaryons using mouse ESCs, demethylation in zebrafish, and global demethylation in mouse primordial germ cells (PGCs) (44-46). The capacity of AID to deaminate $5 \mathrm{mC}$ in a single-stranded DNA was established in vitro (27), although the efficiency of $5 \mathrm{mC}$ deamination by AID was $5-10$ times lower compared to unmethylated-C (47). The same report by Morgan et al. (27) demonstrated that AID mRNA was highly expressed in oocytes and ovaries, and moderately expressed in pluripotent cells (embryonic germ cells, ESCs, and PGCs), which can undergo epigenetic reprograming. Those results indicated that expression of AID was not restricted to activated B cells in the GCs of lymphoid organs and prompted the authors to suggest that the upregulation of AID (and other members of the APOBEC family) in pluripotent tissues could play a role in the epigenetic reprogramming during development. Rai et al. followed that hypothesis and presented the first evidence of the epigenetic role of AID (45). They proposed an active DNA demethylation mechanism in zebrafish embryos in which $5 \mathrm{mC}$ was converted to $\mathrm{T}$ through the cytosine deaminase activity of AID and the subsequent G:T mismatch was repaired by the thymine glycosylase methyl-CpG binding domain protein 4 (MBD4). The injection of methylated DNA (M-DNA) at the single-cell stage induced genome-wide demethylation in zebrafish embryos, allowing the analysis of epigenetic changes in both the injected M-DNA and the bulk genome. After knockdown of AID/APOBEC enzymes using anti-sense morpholino-modified oligonucleotides there was a reduction in demethylation. On the contrary, overexpression of AID (or APOBEC2A/B) and MBD4 induced DNA demethylation of M-DNA and the embryo genome (45).

Thereafter, the production of interspecies heterokaryons (mouse ESCs fused to primary human fibroblasts using polyethylene glycol) allowed the identification of AID-mediated demethylation as a key process for nuclear reprogramming toward pluripotency (44). Transfection experiments with small interference RNAs (siRNAs) for mouse and human AID mRNA $24 \mathrm{~h}$ before fusion inhibited expression of the ESC-specific genes OCT4 and NANOG and reduced the $\mathrm{CpG}$ demethylation in the promoter of those genes. The transient overexpression of the human AID protein before siRNA transfection returned NANOG promoter demethylation and gene expression to normal levels and partially rescued OCT4 demethylation and gene expression.

Primordial germ cells also undergo a process of epigenetic reprogramming, including DNA demethylation, which is pivotal for the acquisition of pluripotency during the germ line development $(48,49)$. Popp et al. demonstrated, on a genome-wide scale, that the genome from fully reprogramed PGCs at E13.5 was extensively hypomethylated and that the absence of AID increased DNA methylation levels, mainly in introns and repetitive elements and also in exons, but not in the promoter regions (46). Importantly, the epigenetic effect of AID on the genome of PGCs was confirmed by two independent techniques: bisulfite next generation sequencing (BS-Seq) and Sequenom MassARRAY. This finding of DNA hypermethylation in cells from $\mathrm{Aicda}^{-/}$mice was restricted to PGCs since the genome-wide methylation levels remained unaffected in the fetus, the placenta, and the sperm. A biological process required during embryogenesis is the epithelialmesenchymal transition (EMT), in which epithelial cells acquire a mesenchymal phenotype characterized by increased migratory capacity and invasiveness and production of extracellular components (50). In addition, EMT is a driving force for tumor metastasis (51). AID is upregulated in epithelial cells during inflammation in vivo $(52-54)$ and by inflammatory factors in vitro $(55,56)$ and was shown to be required for the EMT in both normal mammary epithelial cells and breast cancer cell lines (55). Knockdown of AID in epithelial cell lines blocked the upregulation of SNAI2, $Z E B 1$, and $Z E B 2$, which are master regulator genes for EMT. Those genes inhibited by AID-deficiency presented high levels of methylation in the $\mathrm{CpG}$ islands associated with the promoters and were 
re-expressed in the presence of the demethylating agent 5-aza2 'deoxycitidine, indicating that AID regulated the transcription of EMT-associated genes through DNA demethylation (55).

The in vitro generation of induced pluripotent stem cells (iPSCs) by Yamanaka's group from adult somatic cells through the addition of four transcription factors: OCT4, KLF4, SOX2, and cMYC (57) opened new possibilities for regenerative medicine and autologous therapies. AID was identified as a critical factor for the initiation of mouse embryonic fibroblasts (MEFs) reprogramming to iPSCs (58). Inhibition of AID expression with shRNAs during the first $72 \mathrm{~h}$ after reprogramming induction reduced the number of iPSCs colonies. In addition, rescue experiments with a construct containing a catalytically deficient version of AID (E58Q) demonstrated that the deaminase activity of AID was required for the induction of iPSCs (58). However, experiments performed by different groups with $A i c d a^{-/-}$mice challenged this conclusion because AID-deficient fibroblasts were able to generate iPSCs, although with different kinetics depending on the concentration of virus supernatant, the transfection plasmids, and the culture conditions, including the number of cell passages (59-61). Interestingly, Kumar et al. observed that cells from Aicda ${ }^{-/-}$mice generated iPSCs, but failed to stabilize the expression of pluripotency genes after 3 weeks of culture (59), a phenomenon that correlated with genome hypermethylation in reprogramming cells, especially near RGYW motifs. Additionally, genes that were upregulated later during reprogramming (Rex1, Gdf3, Dnmt3l, Dnmt1, Apobec1, Cbx7, and $Z f p 96$ ) presented higher levels of methylation, both by RRBS and Sequenom MassArray, and were not expressed in the absence of AID (59). The authors proposed that AID was essential for the late phase of reprogramming, which is characterized by the genome-wide erasure of DNA methylation to stabilize a pluripotent phenotype (62).

Although AID is highly expressed in the GCBs and is responsible for the generation of high affinity antibodies through the induction of SHM and CSR $(20,43)$, to date only few studies have addressed the epigenetic role of AID in activated B cells $(15,63)$. An important link between SHM in B cells and DNA hypomethylation has been made by several studies $(19,64,65)$. Endonuclease sensitivity sites within the loci containing CpG nucleotides and located close to J-C intronic enhancers are methylated in somatic cells, but are demethylated in B cells (66-68). Jolly et al. studied DNA methylation and SHM in $J \kappa 5$ region, due to the high density of CpGs and high level of SHMs in those loci. They demonstrated that the locus was heavily methylated in mouse tail DNA, whereas it was totally demethylated in the GCBs from Peyer's patches (64). Studying the Igא transgene and analyzing the $J \kappa 5$ locus they were able to demonstrate that B cells contained a mixture of loci with different state of methylation. Most importantly, the degree of demethylation correlated with the burden of SHM: only demethylated loci contained detectable mutations. This finding led the authors to conclude that transcription and demethylation are requited for SHM, and thus for AID targeting. Our current view is that it is equally possible that demethylation is a consequence of the deaminase activity of AID, which introduces mutations that are subsequently repaired. Hypomethylation along with double strand DNA breaks (DSBs) are likely to be an unwanted consequence of SHM. It is not clear how efficient are DNMTs (DNMT1 and DNMT3b are expressed in the GCBs (15)] in remethylating aberrantly hypomethylated loci. There does not seem to be a detectable loss of $5 \mathrm{mC}$ in the GCBs based on high-performance liquid chromatography (HPLC) measurements in isolated B cell fractions. Nevertheless, the methylation profiling indicates that there is a locus-specific loss of methylation in GCBs (15). DNMT1 localizes to the sites of DSBs and phosphoH2AX foci, and its absence results in increased number of DSBs, making it a likely candidate to remethylate AID-dependent demethylated loci (69). Global post-replicative remethylation of DNA depends on association of DNMT1 with PCNA and replication machinery. In addition, DNMT1 has been shown to associate with various transcription factors and remethylate various genes during not only S phase, but also G1 and G2 phases of the cell cycle $(70,71)$. Hervouet et al. also demonstrated that some genes remained hemi-methylated when leaving $S$ phase and showed a delay in remethylation later in the cell cycle (70). How cell cycle and proliferative rate of GCBs affect global and locus-specific demethylation is an interesting question. It is conceivable that faster proliferation with shorter cell cycle may result in accumulation of hypomethylation. The extent of such passive demethylation is likely to be limited due to the protective effect of Hayflick limit of cell divisions in normal cells $(72,73)$. In cancer, on the other hand, this stochastic accumulation of hypomethylation may contribute to detectable levels of genomic hypomethylation. However, our data in diffuse large B cell lymphoma (DLBCL) cell lines does not reveal different degrees of genome methylation in cell lines with different duration of the cell cycle (unpublished data).

Using microarray-based DNA methylation profiling of NBs and GCBs (15), we demonstrated that hypomethylated loci within GCBs were significantly associated with RGYW-like AIDrecognition motif (74) and CHIP-seq experiments identified AIDbinding sites (42), providing another line of indirect evidence for the link between AID and DNA hypomethylation in B cells. On the other hand, Fritz et al. performed ex vivo experiments using $A i c d a^{-1-}$ mice and reported that the absence of AID did not affect the methylome of activated B cells generated from splenic CD43B cells stimulated with lipopolysaccharide (LPS), interleukin-(IL)4 , and anti-CD40. However, the authors did not exclude that AID could function as a DNA demethylase in vivo (63). Indeed, this ex vivo system of mouse $\mathrm{B}$ cell activation is not equivalent to in vivo $\mathrm{GC}$ reaction. For instance, the mutation rate in activated $\mathrm{B}$ cells is one order of magnitude lower than in GCBs $(41,75,76)$. In addition, Hogenbirk et al. profiled purified GCB from immunized mice using MethylCap-Seq and failed to detect any difference in DNA methylation between wt and Aicda ${ }^{-/-}$mice (77). Nevertheless, it would be necessary to apply higher resolution genome-wide techniques to definitely answer this question. A useful tool to prove the demethylase function of AID in B cells would be a mouse model of GC-specific overexpression of AID, since to date the only available conditional AID-transgenic mice overexpress AID under the CD19 promoter, a molecule expressed in B cells from the early stages of differentiation (78). Therefore, better tools and approaches are necessary to elucidate the role of AID in the DNA demethylation process that occurs in $\mathrm{B}$ cells during their transit through the GC reaction (15). 


\section{PROPOSED MECHANISMS OF ACTIVE DEMETHYLATION}

In order to understand the link between deaminase activity of AID and DNA demethylation, we will review the current state of knowledge of the mechanisms involved in active DNA demethylation. Flowering plants possess a set of DNA glycosylases (DEMETER, ROS1, DML2, and DML3) capable of recognizing and removing $5 \mathrm{mC}$ in a discrete number of loci, such as imprinted genes and silenced transgenes (79-81). Due to the lack of homologs of 5mC DNA glycosylases in vertebrates, other mechanisms of DNA demethylation have been proposed in mammals. It is well established that the BER machinery, which restores nucleotide lesions originated after base deamination, alkylation, or oxidation (82), is involved in the process of active DNA demethylation $(83,84)$. The most frequent lesion in DNA is uracil, which is removed by members of the UDG family: UNG, thymine DNA glycosylase (TDG), single-strand-selective monofunctional uracilDNA glycosylase 1 (SMUG1), and MBD4 (85). The first model for $5 \mathrm{mC}$ demethylation was described in zebrafish embryos and proposed that deamination of $5 \mathrm{mC}$ by AID generated a T:G mismatch that was excised by MBD4, with the cooperation of GADD45, and finally repaired to restore C (45). The formation of a complex containing AID, GADD45, and a DNA glycosylase was also observed in an independent study using HEK293 cells, although the authors identified TDG as the glycosylase of the BER machinery involved in demethylation (86). The discovery of the base 5-hydroxymethyl-2'-deoxycytidine $(5 \mathrm{hmC})(87)$ as a result of the $5 \mathrm{mC}$ oxidation by proteins of the (ten-eleven translocation) TET family (88) enabled the identification of other possible mechanisms of active DNA demethylation (89). One report proposed that the conversion of $5 \mathrm{mC}$ to $5 \mathrm{hmC}$ by TET1 initiated an oxidative-deamination process mediated by the coordinated action of AID/APOBEC proteins and BER pathway, which led to DNA demethylation (90). $5 \mathrm{hmC}$ deamination by AID generated $5 \mathrm{hmU}$, which was excised and repaired by the BER machinery. The specific $5 \mathrm{hmU}$ DNA glycosylases were not identified, but subsequent experiments with $\mathrm{TDG}^{-1-}$ mice suggested that TDG was the DNA glycosylase responsible for the excision of $5 \mathrm{hmU}$ (or T) after deamination by AID of $5 \mathrm{hmC}$ (or C) (86). This model of active DNA demethylation involved the deamination of $5 \mathrm{hmC}$ to $5 \mathrm{hmU}$ by AID/APOBEC proteins, a step that was questioned later on due to the voluminous size of the hydroxymethyl group (91). The biochemical analysis of the AID enzymatic activity using a ssDNA oligonucleotide deamination assay (ODA) (27) indicated that AID could deaminate $\mathrm{C}$ and $5 \mathrm{mC}$, but was unable to remove the side chain at $\mathrm{C} 5$ position from $5 \mathrm{hmC}$ due to the size of the hydroxyl group (91). In line with these results, Nabel et al. demonstrated that the deamination activity of AID diminished with the increasing size of the substituent at five position of $\mathrm{C}$ due to steric hindrance (47). The rate of $5 \mathrm{mC}$ deamination was only $10 \%$ relative to unmethylated-C, and no activity was detected on $5 \mathrm{hmC}$ in vitro. Therefore, if in vitro findings by Nabel et al. also apply in vivo, the role of AID in direct demethylation of $5 \mathrm{mC}$ and $5 \mathrm{hmC}$ may be limited. As an alternative, Petersen-Mahrt's group has recently proposed that methylated-Cs do not have to be directly targeted by AID to be demethylated (92). Using an in vitro resolution (IVR) assay consisting of a methylated plasmid containing
GAL4 DNA-binding sites and a GAL4-AID fusion protein combined with xenopus laevis egg extracts-containing molecules of the BER machinery, this study provides evidence for the activation of different DNA repair pathways after AID-mediated deamination. The short-patch-BER machinery restores only one base, whereas the processive DNA polymerase pathways (long-patchBER or MMR) incorporate multiple nucleotides during the repair process $(82,93,94)$. In that last scenario, the deamination of $\mathrm{C}$ (or $5 \mathrm{mC}$ ) to $\mathrm{U}$ (or T) by AID would promote the activation of a processive DNA polymerase, which would introduce from 2 to $12 \mathrm{nt}$ in the case of the LP-BER (93), or up to $2 \mathrm{~kb}$ of ssDNA if the MMR pathway is triggered (95). As a result, there would be extensive demethylation along the section of DNA around the initial lesion and $5 \mathrm{hmC}$ demethylation would occur independently of targeted AID deamination (92). However, the physiological relevance of this model still needs to be confirmed. All these proposed mechanisms of AID-mediated demethylation rely on the lesion-induced activation of the DNA repair pathways. In all scenarios, the deamination activity of AID introduces a modified base that is targeted by the repair machinery. SHM results from recruitment of the error-prone short-patch BER-especially in Ig genes, leading to a single nucleotide substitution, and a loss of a "methylatable" C. The active and direct loss of methylation is possible if AID deaminates $5 \mathrm{mC}$ to $\mathrm{T}$. On the other hand, if LP-BER or MMR are involved in repair, the outcome is more marked demethylation that extends beyond the original single nucleotide lesion (96). It remains unclear how AID is recruited to its DNA targets. SHM is linked to transcription: AID requires ssDNA to initiate the deamination of $\mathrm{IgV}$ regions (97). Regarding AID partners, it has been demonstrated that stalled Pol II, Spt5, and RPA are necessary for recruitment of AID to Ig and non-Ig targets $(98,99)$. Duke et al. delineated that a combination of Ebox with YY1 and C/EBP- $\beta$ binding sites targets AID in B cells (100). However, it is not known if demethylation and SHM targets are always the same. Hypothetically, the demethylation targets may exceed the numbers of SHM targets due to successful repair, which would leave the AID target site as mutation-free but demethylated. Also, hypomethylated areas are located in introns, intergenic regions and repeat elements rather than promoters, suggesting a different targeting mechanism (46). In contrast, other studies have proposed that active DNA demethylation does not involve AID/APOBECs-mediated deamination, but it occurs through the different intermediates generated after the successive oxidation of $5 \mathrm{hmC}$ by TET proteins: 5-formyl-C (5fC) and 5-carboxyl-C $(5 \mathrm{caC})$, which are excised by TDG and replaced by unmodified cytosine $(101,102)$. Finally, it has been demonstrated recently that TETs are able to oxidize T to $5 \mathrm{hmU}$ in mouse ESCs (103). This finding unveils another possible mechanism of demethylation consisting of AID-mediated deamination of $\mathrm{mC}$ to $\mathrm{T}$ followed by conversion of $\mathrm{T}$ to $5 \mathrm{hmU}$ by TET proteins. Based on the previously mentioned results, it seems reasonable to conclude that both AID-dependent and TET-dependent mechanisms participate in the active demethylation of the genome (Figure 1). To what extent they are interconnected or which one is preferentially activated depending on the cell type needs to be further investigated. 


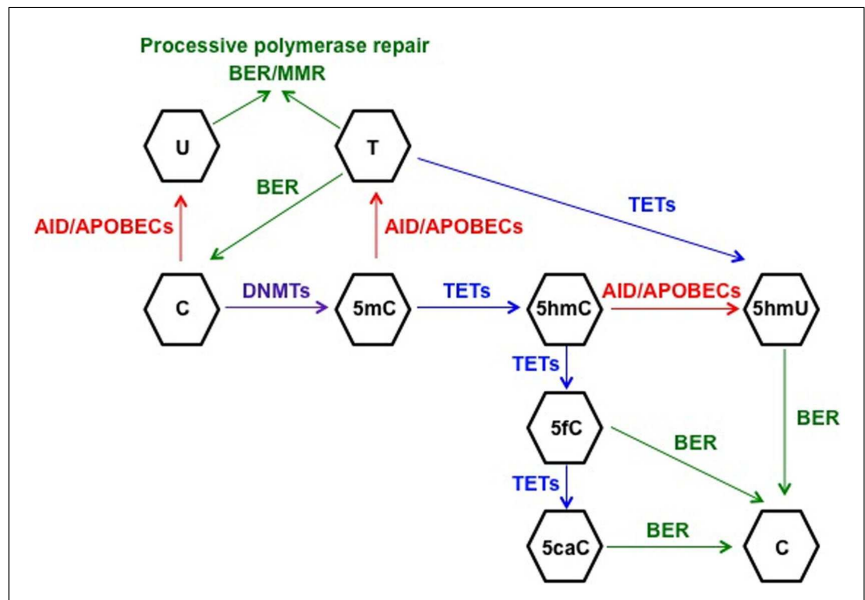

FIGURE 1 | Schematic representation of the proposed mechanisms for active DNA demethylation. DNMTs catalyze the methylation of cytosine (C) to 5-methyl-C $(5 \mathrm{mC})$, which can be deaminated to thymine (T) by AID. The generated mismatch can be repaired by the short-patch BER machinery, restoring $C$, or by one of the processive repair pathways (long-patch BER or MMR), leading to demethylation of a fragment of DNA This machinery involving processive DNA polymerases can also repair the uracil:guanine ( $\mathrm{dU}: \mathrm{dG}$ ) mismatches generated after $\mathrm{C}$ deamination to $\mathrm{U}$. On the other hand, TET-mediated hydroxylation of $5 \mathrm{mC}$ generates

5-hydroxymethyl-C ( $5 \mathrm{hmC}$ ), which can be deaminated by AID/APOBECs to 5-hydroxymethyl-U (5hmU) and replaced by $\mathrm{C}$ through BER. $5 \mathrm{hmC}$ can be further oxidized by TETs proteins to 5 -formyl-C $(5 f C)$ and 5 -carboxyl-C $(5 \mathrm{caC})$, leading to activation of BER to restore $\mathrm{C}$. Finally, another potential mechanism of active DNA demethylation would involve $5 \mathrm{mC}$ deamination to $T$ and TET-mediated oxidation of $T$ to $5 \mathrm{hmU}$, which would be replaced by $C$ through BER, although this model has not been proven as yet.

\section{DNA HYPOMETHYLATION AND CANCER}

The question of AID activity, its possible link to DNA hypomethylation and predisposition to cancer is a fundamental one. At the moment, only a tenuous link exists between AID-induced SHM and DNA hypomethylation in B cells and B cell lymphomas. There is a large body of evidence though linking hypomethylation to cancer $(70,104,105)$. Many subtypes of lymphomas reveal genomewide hypomethylation. Wahlfors et al. made an early observation that chronic lymphocytic leukemia (CLL) genome undergoes global loss of methylation using digestion of genomic DNA with isoschizomer enzymes HpaII and MspI, followed by validation using HPLC (104). More recently, these findings were confirmed by whole methylome sequencing studies, which revealed that aberrant hypomethylation was centered in repetitive sequences, like ALU and LINES and were particularly pronounced in CLL with TP53 mutations (106). A subset of DLBCLs also revealed loss of DNA methylation, as demonstrated by Chambwe et al. (107). Methylome interrogation in the follicular lymphoma (FL) cell line $\mathrm{RL}$ and in CD19+ $\mathrm{B}$ cells using 454 sequencing technology (108) revealed hypermethylation in the promoters, but hypomethylation in intra- and intergenic areas of the genome.

DNA methylation patterns in all tissues and cell types are a result of two main forces: deterministic patterning and stochastic changes [reviewed in Ref. (109)]. Deterministic changes in DNA methylation reflect the tissue-specific forces, which are dependent on transcription factors and epigenetic factors that reflect the tissue type and determine cellular identity. On the other hand, the stochastic changes reflect the cell-to-cell variability, with individual cells at the same tissue and differentiation stage displaying epigenetic heterogeneity. There are several possible sources of stochastic variability: aging, ambient mutagens, oxidative damage, errors, and off-target activity of epigenetic enzymatic factors $(110,111)$. Several mechanisms have been proposed to contribute to DNA hypomethylation in normal development and disease, which to different degrees can explain deterministic and stochastic DNA hypomethylation. One explanation is a possible reduction of intracellular concentration of DNA methyl donor S-adenosylmethionine (AdoMet) or an increased concentration of the product of the reaction and its inhibitor S-Adenosylhomocysteine (AdoHcy) (112). Methyl-deficient diet has been shown to lead to AdoMet deficiency in a mouse model (113), but has not been proven to contribute to carcinogenesis in humans. Another logical explanation for DNA hypomethylation would be the decreased activity of DNMTs or increased activity of demethylases. Published observations in tumors and normal development suggest that hypomethylation does not correlate with decreased expression of DNMTs or their mutations (114-116). On the other hand, active demethylation can take place either by the action of yet unidentified demethylases or through DNA repair process. Enzymatic demethylation is not favored because of the stability of the chemical bond. Ramchandani et al. reported the biochemical purification of a DNA demethylase from tumor cells (117). The same group demonstrated that the rate limiting step in the reaction is initiation of demethylation, which is sequence specific and progresses in a processive manner sliding along the DNA and demethylating CpGs in cis position (118). MBD2 was demonstrated to possess demethylase activity in biochemical in vitro experiments and in solid cancers, but its function as demethylase remains controversial $(119,120)$. Another possibility is modification of DNA nucleotides by deaminases resulting in eventual excision and repair of that nucleotide and loss of methylation. AID is the key candidate for this mechanism of demethylation, as discussed before. AID is known to contribute to chromosomal instability and induce chromosomal translocations by inducing DSBs (see below). B lymphocytes from IgкAID-transgenic mice showed increased number of chromosomal translocations $(6 \%$ of cells) and increased frequency of DNA breaks (8\% of cells) (121). The contribution of hypomethylation to AID-dependent genomic instability has not been addressed and warrants further investigation.

The biological effect of DNA hypomethylation is its contribution to reactivation of transposable elements, activation of oncogenes, and increased chromosomal fragility, as demonstrated elegantly by Gaudet et al. in experiments with hypomorphic DNMT1 mice $(122,123)$. Mice with low DNMT1 expression at $10 \%$ of wild type level demonstrated marked reduction in genome-wide DNA methylation and revealed significant increase in genomic instability and activation of proto-oncogenes, like $c$-Myc (124). The maintenance of methylation in mammalian cells is accomplished by DNMTs, particularly DNMT1 and its complex with PCNA and UHFR1. Disruption of this complex results in global 
hypomethylation and serves as a biomarker of poor prognosis in GBM tumors (125).

\section{ROLE OF AID IN LYMPHOMAGENESIS}

AID is expressed in half of Burkitt lymphomas (BLs), 30\% DLBCLs and $25 \% \mathrm{FLs}$, and is absent in B cell precursor lymphoblastic leukemia and mantle cell lymphomas $(126,127)$. Due to its DNA mutator capacity, AID activity represents a potential risk for genomic instability. It is clear that AID can introduce point mutations in Ig and non-Ig genes and also induce chromosome translocations involving oncogenes, which contribute to the development of B cell neoplasms (128). Pasqualucci et al. found that proto-oncogenes such as PIM1, MYC, RHOH/TTF, and PAX5 were aberrantly mutated in more than $50 \%$ of the DLBCLs cases analyzed, probably due to failure of the SHM pathway (129). In addition, chromosomal translocations are frequent in lymphomas and myelomas, including DLBCLs, BLs, multiple myeloma, and mouse plasmacytoma $(130,131)$. Specifically, translocations between $c$ MYC and the Ig $\mathrm{C}_{\mathrm{H}}$ genes $(c-M Y C / I g H)$ are a hallmark of BLs and were demonstrated to be AID-dependent, since AID-deficiency eliminated the presence of canonical $c M y c$ translocations in BCL6 or Bcl-xL transgenic mice $(132,133)$, although the frequency of DSBs was lower in $c-M y c$ than in $I g H$ (76). Moreover, mutations in the anti-apoptotic protein BCL2 are frequent in DLBCLs and are enriched in the AID-binding motif WRCY (134).

Multiple mouse models have been established to study lymphomagenesis in vivo, and more specifically to clarify the role of AID in the induction and development of B cell neoplasms. Experiments with I $\mu$ HABCL6 transgenic mice, which develop lymphomas due to the deregulated expression of the transcriptional repressor BCL6 under the control of the IgH I $\mu$ promoter (135), demonstrated that AID had a role in lymphomagenesis (136). AID-deficiency in IMHABCL6 background prevented the formation of GC-derived lymphomas. This effect was not observed when crossing Aicda ${ }^{-1-}$ mice with other lymphomaprone mouse models such as $\lambda$ MYC mice, which develop pre-GCderived lymphomas, or $\lambda \mathrm{MYC} / \mathrm{I} \mu \mathrm{HABCL} 6$ mice, characterized by the formation of post-GC-derived malignancies. The same report showed that ex vivo stimulated B cells from I $\mu$ HABCL6 mice presented a high number of $c-M y c / I g H$ translocations, which were not present in activated I $\mu$ HABCL6/Aicda ${ }^{-1}$ cells. The authors proposed that AID-mediated translocations contributed to lymphoma formation (136). Another study reported that AID activity determined the frequency of lymphocytes with $c-M y c / I g H$ translocations, influencing the incidence of $\mathrm{B}$ cell tumor development in a mouse model of plasmacytoma (137). An independent group demonstrated the link between AID-mediated chromosome translocations and mature B cell lymphomas using another transgenic mouse strain, which expressed AID under the control regulatory elements of the light chain Igк (121). In this experimental design, deregulated AID expression generated DSBs in the genome of B cells, inducing $c-M y c / I g H$ chromosome translocations. Nonetheless, AID overexpression was not sufficient to drive $B$ cell lymphomagenesis, requiring the concomitant loss of the tumor suppressor p53 in that model (121). The generation of a transgenic mouse strain with sporadic $c-M y c$ activation in GCBs ( $\mathrm{Vk}^{\star} \mathrm{MYC}$ ), which led to a multiple myeloma phenotype, indicated that AID-mediated SHM was required for the aberrant $c$ $M y c$ expression and the subsequent plasma cells expansion (138). Constitutive expression of AID using a transgenic mouse model, which expresses AID under the control of the ubiquitous CAG promoter, led to $\mathrm{T}$ cell lymphomas containing no translocations but abundant point mutations in $c-M y c$ and the TCR genes (139). Bone marrow transplantation experiments with AID-transduced cells also resulted in the development of T-lymphomas, with frequent point mutations in Notchl, PTEN, and $c-M y c$. Noteworthy, some of the mice presented B-lymphomas after transplantation. Pax5 and Ebf1 were mutated in these B cell-derived malignancies and no chromosome translocations were found (140). The aforementioned mouse models proposed different mechanisms of AID-mediated genomic instability, focused on the analysis of somatic mutations or translocations involving proto-oncogenes generated as a consequence of the deaminase activity of AID. Intriguingly, the role of AID activity in the epigenetic stability of the genome and its implication in lymphomagenesis remain largely unexplored. De et al. (141) analyzed the DNA methylation patterning in three subtypes of primary lymphomas: FL, GCBDLBCL, and ABC-DLBCL (142), which differs in their level of aggressiveness (FL $<$ GCB-DLBCL $<$ ABC-DLBCL). This study demonstrated that normal GCBs presented higher level of epigenetic heterogeneity than NBs, and also that inter-sample and intra-sample methylation heterogeneity increased with lymphoma aggressiveness, correlating with adverse outcome (141). Trying to discover the cause for the abnormal DNA methylation patterns in B cell lymphomas, the authors found that the promoters of the targets of BCL6 and EZH2 showed an aberrant hypermethylated status compared to normal B cells. On the contrary, AID target genes presented an abnormal promoter hypomethylation. In addition, the expression level of AID was significantly correlated with genome-wide aberrant hypomethylation (141). This result, along with the established role of AID in active DNA demethylation during normal development and also with the significantly higher hypomethylation in GCBs compared to NBs in regions enriched for the putative AID-binding site RGYW, suggests an epigenetic role for AID during GC transit of normal B cells and in GC-derived lymphomagenesis. Such a role needs to be formally proven and will have great implications on our understanding of B cell biology.

\section{AUTHOR CONTRIBUTIONS}

Pilar M. Dominguez and Rita Shaknovich conceptualized and wrote the manuscript.

\section{ACKNOWLEDGMENTS}

We would like to thank Dr. A. Melnick, Dr. O. Elemento, Dr. J. Chaudhuri, and Dr. T. Evans for useful discussions. Pilar M. Dominguez is supported by STARR Cancer Consortium grant; Rita Shaknovich is supported by STARR Cancer Consortium grant and LLS TRP grant 6304-11.

\section{REFERENCES}

1. Jaenisch R, Bird A. Epigenetic regulation of gene expression: how the genome integrates intrinsic and environmental signals. Nat Genet (2003) 33(Suppl):245-54. doi:10.1038/ng1089 
2. Li G, Zan H, Xu Z, Casali P. Epigenetics of the antibody response. Trends Immunol (2013) 34(9):460-70. doi:10.1016/j.it.2013.03.006

3. Jones PA, Takai D. The role of DNA methylation in mammalian epigenetics. Science (2001) 293(5532):1068-70. doi:10.1126/science.1063852

4. Bird A. DNA methylation patterns and epigenetic memory. Genes Dev (2002) 16(1):6-21. doi:10.1101/gad.947102

5. Robertson KD. DNA methylation and chromatin - unraveling the tangled web. Oncogene (2002) 21(35):5361-79. doi:10.1038/sj.onc.1205609

6. Egger G, Liang G, Aparicio A, Jones PA. Epigenetics in human disease and prospects for epigenetic therapy. Nature (2004) 429(6990):457-63. doi:10. 1038 /nature 02625

7. Lister R, Mukamel EA, Nery JR, Urich M, Puddifoot CA, Johnson ND, et al. Global epigenomic reconfiguration during mammalian brain development. Science (2013) 341(6146):1237905. doi:10.1126/science.1237905

8. Head JA. Patterns of DNA methylation in animals: an ecotoxicological perspective. Integr Comp Biol (2014) 54(1):77-86. doi:10.1093/icb/icu025

9. Goll MG, Bestor TH. Eukaryotic cytosine methyltransferases. Annu Rev Biochem (2005) 74:481-514. doi:10.1146/annurev.biochem.74.010904.153721

10. He XJ, Chen T, Zhu JK. Regulation and function of DNA methylation in plants and animals. Cell Res (2011) 21(3):442-65. doi:10.1038/cr.2011.23

11. Gong Z, Zhu JK. Active DNA demethylation by oxidation and repair. Cell Res (2011) 21(12):1649-51. doi:10.1038/cr.2011.140

12. Ji H, Ehrlich LI, Seita J, Murakami P, Doi A, Lindau P, et al. Comprehensive methylome map of lineage commitment from haematopoietic progenitors. Nature (2010) 467(7313):338-42. doi:10.1038/nature09367

13. Hodges E, Molaro A, Dos Santos CO, Thekkat P, Song Q, Uren PJ, et al. Directional DNA methylation changes and complex intermediate states accompany lineage specificity in the adult hematopoietic compartment. Mol Cell (2011) 44(1):17-28. doi:10.1016/j.molcel.2011.08.026

14. Zilbauer M, Rayner TF, Clark C, Coffey AJ, Joyce CJ, Palta P, et al. Genomewide methylation analyses of primary human leukocyte subsets identifies functionally important cell-type-specific hypomethylated regions. Blood (2013) 122(25):e52-60. doi:10.1182/blood-2013-05-503201

15. Shaknovich R, Cerchietti L, Tsikitas L, Kormaksson M, De S, Figueroa ME, et al. DNA methyltransferase 1 and DNA methylation patterning contribute to germinal center B-cell differentiation. Blood (2011) 118(13):3559-69. doi:10.1182/blood-2011-06-357996

16. Lai AY, Mav D, Shah R, Grimm SA, Phadke D, Hatzi K, et al. DNA methylation profiling in human $\mathrm{B}$ cells reveals immune regulatory elements and epigenetic plasticity at Alu elements during B-cell activation. Genome Res (2013) 23(12):2030-41. doi:10.1101/gr.155473.113

17. Muramatsu M, Kinoshita K, Fagarasan S, Yamada S, Shinkai Y, Honjo T. Class switch recombination and hypermutation require activation-induced cytidine deaminase (AID), a potential RNA editing enzyme. Cell (2000) 102(5):553-63. doi:10.1016/S0092-8674(00)00078-7

18. Conticello SG. The AID/APOBEC family of nucleic acid mutators. Genome Biol (2008) 9(6):229. doi:10.1186/gb-2008-9-6-229

19. Zan H, Casali P. Regulation of Aicda expression and AID activity. Autoimmunity (2013) 46(2):83-101. doi:10.3109/08916934.2012.749244

20. Storb U, Stavnezer J. Immunoglobulin genes: generating diversity with AID and UNG. Curr Biol (2002) 12(21):R725-7. doi:10.1016/S0960-9822(02)01247-2

21. Teng G, Papavasiliou FN. Immunoglobulin somatic hypermutation. Annu Rev Genet (2007) 41:107-20. doi:10.1146/annurev.genet.41.110306.130340

22. Chaudhuri J, Alt FW. Class-switch recombination: interplay of transcription, DNA deamination and DNA repair. Nat Rev Immunol (2004) 4(7):541-52. doi:10.1038/nri1425

23. Stavnezer J, Guikema JE, Schrader CE. Mechanism and regulation of class switch recombination. Annu Rev Immunol (2008) 26:261-92. doi:10.1146/ annurev.immunol.26.021607.090248

24. Xu Z, Zan H, Pone EJ, Mai T, Casali P. Immunoglobulin class-switch DNA recombination: induction, targeting and beyond. Nat Rev Immunol (2012) 12(7):517-31. doi:10.1038/nri3216

25. Honjo T, Nagaoka H, Shinkura R, Muramatsu M. AID to overcome the limitations of genomic information. Nat Immunol (2005) 6(7):655-61. doi:10.1038/ ni1218

26. Peled JU, Kuang FL, Iglesias-Ussel MD, Roa S, Kalis SL, Goodman MF, et al. The biochemistry of somatic hypermutation. Annu Rev Immunol (2008) 26:481-511. doi:10.1146/annurev.immunol.26.021607.090236
27. Morgan HD, Dean W, Coker HA, Reik W, Petersen-Mahrt SK. Activationinduced cytidine deaminase deaminates 5-methylcytosine in DNA and is expressed in pluripotent tissues: implications for epigenetic reprogramming. J Biol Chem (2004) 279(50):52353-60. doi:10.1074/jbc.M407695200

28. Cattoretti G, Buettner M, Shaknovich R, Kremmer E, Alobeid B, Niedobitek G. Nuclear and cytoplasmic AID in extrafollicular and germinal center B cells. Blood (2006) 107(10):3967-75. doi:10.1182/blood-2005-10-4170

29. Pone EJ, Zan H, Zhang J, Al-Qahtani A, Xu Z, Casali P. Toll-like receptors and B-cell receptors synergize to induce immunoglobulin class-switch DNA recombination: relevance to microbial antibody responses. Crit Rev Immunol (2010) 30(1):1-29. doi:10.1615/CritRevImmunol.v30.i1.10

30. Shaffer AL, Lin KI, Kuo TC, Yu X, Hurt EM, Rosenwald A, et al. Blimp-1 orchestrates plasma cell differentiation by extinguishing the mature B cell gene expression program. Immunity (2002) 17(1):51-62. doi:10.1016/S10747613(02)00335-7

31. Crouch EE, Li Z, Takizawa M, Fichtner-Feigl S, Gourzi P, Montano C, et al. Regulation of AID expression in the immune response. J Exp Med (2007) 204(5):1145-56. doi:10.1084/jem.20061952

32. Gourzi P, Leonova T, Papavasiliou FN. Viral induction of AID is independent of the interferon and the toll-like receptor signaling pathways but requires NF-kappaB. J Exp Med (2007) 204(2):259-65. doi:10.1084/jem.20061801

33. Machida K, Cheng KT, Sung VM, Shimodaira S, Lindsay KL, Levine AM, et al. Hepatitis $\mathrm{C}$ virus induces a mutator phenotype: enhanced mutations of immunoglobulin and protooncogenes. Proc Natl Acad Sci U S A (2004) 101(12):4262-7. doi:10.1073/pnas.0303971101

34. Tobollik S, Meyer L, Buettner M, Klemmer S, Kempkes B, Kremmer E, et al. Epstein-Barr virus nuclear antigen 2 inhibits AID expression during EBVdriven B-cell growth. Blood (2006) 108(12):3859-64. doi:10.1182/blood-200605-021303

35. Berek C, Milstein C. Mutation drift and repertoire shift in the maturation of the immune response. Immunol Rev (1987) 96:23-41. doi:10.1111/j.1600065X.1987.tb00507.x

36. Rajewsky K, Forster I, Cumano A. Evolutionary and somatic selection of the antibody repertoire in the mouse. Science (1987) 238(4830):1088-94. doi: $10.1126 /$ science. 3317826

37. Shen HM, Peters A, Baron B, Zhu X, Storb U. Mutation of BCL-6 gene in normal B cells by the process of somatic hypermutation of Ig genes. Science (1998) 280(5370):1750-2. doi:10.1126/science.280.5370.1750

38. Pasqualucci L, Migliazza A, Fracchiolla N, William C, Neri A, Baldini L, et al. BCL-6 mutations in normal germinal center B cells: evidence of somatic hypermutation acting outside Ig loci. Proc Natl Acad Sci U S A (1998) 95(20):11816-21. doi:10.1073/pnas.95.20.11816

39. Gordon MS, Kanegai CM, Doerr JR, Wall R. Somatic hypermutation of the B cell receptor genes B29 (Igbeta, CD79b) and mb1 (Igalpha, CD79a). Proc Natl Acad Sci U S A (2003) 100(7):4126-31. doi:10.1073/pnas.0735266100

40. Muschen M, Re D, Jungnickel B, Diehl V, Rajewsky K, Kuppers R. Somatic mutation of the CD95 gene in human B cells as a side-effect of the germinal center reaction. J Exp Med (2000) 192(12):1833-40. doi:10.1084/jem.192.12.1833

41. Liu M, Duke JL, Richter DJ, Vinuesa CG, Goodnow CC, Kleinstein SH, et al. Two levels of protection for the B cell genome during somatic hypermutation. Nature (2008) 451(7180):841-5. doi:10.1038/nature06547

42. Yamane A, Resch W, Kuo N, Kuchen S, Li Z, Sun HW, et al. Deep-sequencing identification of the genomic targets of the cytidine deaminase AID and its cofactor RPA in B lymphocytes. Nat Immunol (2011) 12(1):62-9. doi:10.1038/ ni. 1964

43. Kumar R, DiMenna LJ, Chaudhuri J, Evans T. Biological function of activationinduced cytidine deaminase (AID). Biomed J (2014) 37(5):269-83. doi:10. 4103/2319-4170.128734

44. Bhutani N, Brady JJ, Damian M, Sacco A, Corbel SY, Blau HM. Reprogramming towards pluripotency requires AID-dependent DNA demethylation. Nature (2010) 463(7284):1042-7. doi:10.1038/nature08752

45. Rai K, Huggins IJ, James SR, Karpf AR, Jones DA, Cairns BR. DNA demethylation in zebrafish involves the coupling of a deaminase, a glycosylase, and gadd45. Cell (2008) 135(7):1201-12. doi:10.1016/j.cell.2008.11.042

46. Popp C, Dean W, Feng S, Cokus SJ, Andrews S, Pellegrini M, et al. Genomewide erasure of DNA methylation in mouse primordial germ cells is affected by AID deficiency. Nature (2010) 463(7284):1101-5. doi:10.1038/ nature08829 
47. Nabel CS, Jia H, Ye Y, Shen L, Goldschmidt HL, Stivers JT, et al. AID/APOBEC deaminases disfavor modified cytosines implicated in DNA demethylation. Nat Chem Biol (2012) 8(9):751-8. doi:10.1038/nchembio.1042

48. Hajkova P, Erhardt S, Lane N, Haaf T, El-Maarri O, Reik W, et al. Epigenetic reprogramming in mouse primordial germ cells. Mech Dev (2002) 117(12):15-23. doi:10.1016/S0925-4773(02)00181-8

49. Sasaki H, Matsui Y. Epigenetic events in mammalian germ-cell development: reprogramming and beyond. Nat Rev Genet (2008) 9(2):129-40. doi:10.1038/ nrg2295

50. Hay ED. An overview of epithelio-mesenchymal transformation. Acta Anat (1995) 154(1):8-20. doi:10.1159/000147748

51. Kalluri R, Weinberg RA. The basics of epithelial-mesenchymal transition. J Clin Invest (2009) 119(6):1420-8. doi:10.1172/JCI39104

52. Komori J, Marusawa H, Machimoto T, Endo Y, Kinoshita K, Kou T, et al. Activation-induced cytidine deaminase links bile duct inflammation to human cholangiocarcinoma. Hepatology (2008) 47(3):888-96. doi:10.1002/hep.22125

53. Endo Y, Marusawa H, Kou T, Nakase H, Fujii S, Fujimori T, et al. Activationinduced cytidine deaminase links between inflammation and the development of colitis-associated colorectal cancers. Gastroenterology (2008) 135(3):e1-3. doi:10.1053/j.gastro.2008.06.091

54. Matsumoto Y, Marusawa H, Kinoshita K, Endo Y, Kou T, Morisawa T, et al. Helicobacter pylori infection triggers aberrant expression of activation-induced cytidine deaminase in gastric epithelium. Nat Med (2007) 13(4):470-6. doi:10.1038/nm1566

55. Munoz DP, Lee EL, Takayama S, Coppe JP, Heo SJ, Boffelli D, et al. Activationinduced cytidine deaminase (AID) is necessary for the epithelial-mesenchymal transition in mammary epithelial cells. Proc Natl Acad Sci U S A (2013) 110(32):E2977-86. doi:10.1073/pnas.1301021110

56. Liu Y, Mukhopadhyay P, Pisano MM, Lu X, Huang L, Lu Q, et al. Repression of Zebl and hypoxia cause sequential mesenchymal-to-epithelial transition and induction of aid, Oct4, and Dnmt1, leading to immortalization and multipotential reprogramming of fibroblasts in spheres. Stem Cells (2013) 31(7):1350-62. doi:10.1002/stem.1382

57. Takahashi K, Yamanaka S. Induction of pluripotent stem cells from mouse embryonic and adult fibroblast cultures by defined factors. Cell (2006) 126(4):663-76. doi:10.1016/j.cell.2006.07.024

58. Bhutani N, Decker MN, Brady JJ, Bussat RT, Burns DM, Corbel SY, et al. A critical role for AID in the initiation of reprogramming to induced pluripotent stem cells. FASEB J (2013) 27(3):1107-13. doi:10.1096/fj.12-222125

59. Kumar R, DiMenna L, Schrode N, Liu TC, Franck P, Munoz-Descalzo S, et al. AID stabilizes stem-cell phenotype by removing epigenetic memory of pluripotency genes. Nature (2013) 500(7460):89-92. doi:10.1038/nature12299

60. Habib O, Habib G, Do JT, Moon SH, Chung HM. Activation-induced deaminase-coupled DNA demethylation is not crucial for the generation of induced pluripotent stem cells. Stem Cells Dev (2014) 23(3):209-18. doi:10.1089/scd.2013.0337

61. Shimamoto R, Amano N, Ichisaka T, Watanabe A, Yamanaka S, Okita K. Generation and characterization of induced pluripotent stem cells from Aid-deficient mice. PLoS One (2014) 9(4):e94735. doi:10.1371/journal.pone.0094735

62. Polo JM, Anderssen E, Walsh RM, Schwarz BA, Nefzger CM, Lim SM, et al. A molecular roadmap of reprogramming somatic cells into iPS cells. Cell (2012) 151(7):1617-32. doi:10.1016/j.cell.2012.11.039

63. Fritz EL, Rosenberg BR, Lay K, Mihailovic A, Tuschl T, Papavasiliou FN. A comprehensive analysis of the effects of the deaminase AID on the transcriptome and methylome of activated B cells. Nat Immunol (2013) 14(7):749-55. doi:10.1038/ni.2616

64. Jolly CJ, Neuberger MS. Somatic hypermutation of immunoglobulin kappa transgenes: association of mutability with demethylation. Immunol Cell Biol (2001) 79(1):18-22. doi:10.1046/j.1440-1711.2001.00968.x

65. Larijani M, Frieder D, Sonbuchner TM, Bransteitter R, Goodman MF, Bouhassira EE, et al. Methylation protects cytidines from AID-mediated deamination. Mol Immunol (2005) 42(5):599-604. doi:10.1016/j.molimm.2004.09.007

66. Fraenkel S, Mostoslavsky R, Novobrantseva TI, Pelanda R, Chaudhuri J, Esposito G, et al. Allelic 'choice' governs somatic hypermutation in vivo at the immunoglobulin kappa-chain locus. Nat Immunol (2007) 8(7):715-22. doi:10.1038/ni1476

67. Mather EL, Perry RP. Methylation status and DNase I sensitivity of immunoglobulin genes: changes associated with rearrangement. Proc Natl Acad Sci U S A (1983) 80(15):4689-93. doi:10.1073/pnas.80.15.4689
68. Storb U, Arp B. Methylation patterns of immunoglobulin genes in lymphoid cells: correlation of expression and differentiation with undermethylation. Proc Natl Acad Sci U S A (1983) 80(21):6642-6. doi:10.1073/pnas.80.21. 6642

69. Ha K, Lee GE, Palii SS, Brown KD, Takeda Y, Liu K, et al. Rapid and transient recruitment of DNMT1 to DNA double-strand breaks is mediated by its interaction with multiple components of the DNA damage response machinery. Hum Mol Genet (2011) 20(1):126-40. doi:10.1093/hmg/ddq451

70. Hervouet E, Nadaradjane A, Gueguen M, Vallette FM, Cartron PF. Kinetics of DNA methylation inheritance by the Dnmtl-including complexes during the cell cycle. Cell Div (2012) 7:5. doi:10.1186/1747-1028-7-5

71. Hervouet E, Vallette FM, Cartron PF. Dnmt1/transcription factor interactions: an alternative mechanism of DNA methylation inheritance. Genes Cancer (2010) 1(5):434-43. doi:10.1177/1947601910373794

72. Hayflick L. The limited in vitro lifetime of human diploid cell strains. Exp Cell Res (1965) 37:614-36. doi:10.1016/0014-4827(65)90211-9

73. Kim MJ, Kim MH, Kim SA, Chang JS. Age-related deterioration of hematopoietic stem cells. Int J Stem Cells (2008) 1(1):55-63. doi:10.15283/ ijsc.2008.1.1.55

74. Martin A, Bardwell PD, Woo CJ, Fan M, Shulman MJ, Scharff MD. Activationinduced cytidine deaminase turns on somatic hypermutation in hybridomas. Nature (2002) 415(6873):802-6. doi:10.1038/nature714

75. McKean D, Huppi K, Bell M, Staudt L, Gerhard W, Weigert M. Generation of antibody diversity in the immune response of $\mathrm{BALB} / \mathrm{c}$ mice to influenza virus hemagglutinin. Proc Natl Acad Sci U S A (1984) 81(10):3180-4. doi:10.1073/pnas.81.10.3180

76. Robbiani DF, Bothmer A, Callen E, Reina-San-Martin B, Dorsett Y, Difilippantonio S, et al. AID is required for the chromosomal breaks in c-myc that lead to c-myc/IgH translocations. Cell (2008) 135(6):1028-38. doi:10.1016/j.cell. 2008.09.062

77. Hogenbirk MA, Heideman MR, Velds A, van den Berk PC, Kerkhoven RM, van Steensel B, et al. Differential programming of B cells in AID deficient mice. PLoS One (2013) 8(7):e69815. doi:10.1371/journal.pone.0069815

78. Muto T, Okazaki IM, Yamada S, Tanaka Y, Kinoshita K, Muramatsu M, et al. Negative regulation of activation-induced cytidine deaminase in B cells. Proc Natl Acad Sci U S A (2006) 103(8):2752-7. doi:10.1073/pnas.0510970103

79. Choi Y, Gehring M, Johnson L, Hannon M, Harada JJ, Goldberg RB, et al. DEMETER, a DNA glycosylase domain protein, is required for endosperm gene imprinting and seed viability in arabidopsis. Cell (2002) 110(1):33-42. doi:10.1016/S0092-8674(02)00807-3

80. Gong Z, Morales-Ruiz T, Ariza RR, Roldan-Arjona T, David L, Zhu JK. ROS1, a repressor of transcriptional gene silencing in Arabidopsis, encodes a DNA glycosylase/lyase. Cell (2002) 111(6):803-14. doi:10.1016/S00928674(02)01133-9

81. Jullien PE, Kinoshita T, Ohad N, Berger F. Maintenance of DNA methylation during the Arabidopsis life cycle is essential for parental imprinting. Plant Cell (2006) 18(6):1360-72. doi:10.1105/tpc.106.041178

82. Kim YJ, Wilson DM III. Overview of base excision repair biochemistry. Curr Mol Pharmacol (2012) 5(1):3-13. doi:10.2174/1874467211205010003

83. Gehring M, Reik W, Henikoff S. DNA demethylation by DNA repair. Trends Genet (2009) 25(2):82-90. doi:10.1016/j.tig.2008.12.001

84. Zhu JK. Active DNA demethylation mediated by DNA glycosylases. Annu Rev Genet (2009) 43:143-66. doi:10.1146/annurev-genet-102108-134205

85. Zharkova DO, Mechetina GV, Nevinskya GA. Uracil-DNA glycosylase: Structural, thermodynamic and kinetic aspects of lesion search and recognition. Mutat Res (2010) 685(1-2):11-20. doi:10.1016/j.mrfmmm.2009.10.017

86. Cortellino S, Xu J, Sannai M, Moore R, Caretti E, Cigliano A, et al. Thymine DNA glycosylase is essential for active DNA demethylation by linked deamination-base excision repair. Cell (2011) 146(1):67-79. doi:10.1016/j.cell. 2011.06.020

87. Kriaucionis S, Heintz N. The nuclear DNA base 5-hydroxymethylcytosine is present in Purkinje neurons and the brain. Science (2009) 324(5929):929-30. doi:10.1126/science.1169786

88. Tahiliani M, Koh KP, Shen Y, Pastor WA, Bandukwala H, Brudno Y, et al. Conversion of 5-methylcytosine to 5-hydroxymethylcytosine in mammalian DNA by MLL partner TET1. Science (2009) 324(5929):930-5. doi:10.1126/science. 1170116

89. Wu SC, Zhang Y. Active DNA demethylation: many roads lead to Rome. Nat Rev Mol Cell Biol (2010) 11(9):607-20. doi:10.1038/nrm2950 
90. Guo JU, Su Y, Zhong C, Ming GL, Song H. Hydroxylation of 5-methylcytosine by TET1 promotes active DNA demethylation in the adult brain. Cell (2011) 145(3):423-34. doi:10.1016/j.cell.2011.03.022

91. Rangam G, Schmitz KM, Cobb AJ, Petersen-Mahrt SK. AID enzymatic activity is inversely proportional to the size of cytosine C5 orbital cloud. PLoS One (2012) 7(8):e43279. doi:10.1371/journal.pone.0043279

92. Franchini DM, Chan CF, Morgan H, Incorvaia E, Rangam G, Dean W, et al. Processive DNA demethylation via DNA deaminase-induced lesion resolution. PLoS One (2014) 9(7):e97754. doi:10.1371/journal.pone.0097754

93. Robertson AB, Klungland A, Rognes T, Leiros I. DNA repair in mammalian cells: base excision repair: the long and short of it. Cell Mol Life Sci (2009) 66(6):981-93. doi:10.1007/s00018-009-8736-z

94. Li GM. Mechanisms and functions of DNA mismatch repair. Cell Res (2008) 18(1):85-98. doi:10.1038/cr.2007.115

95. Jiricny J. The multifaceted mismatch-repair system. Nat Rev Mol Cell Biol (2006) 7(5):335-46. doi:10.1038/nrm1907

96. Fritz EL, Papavasiliou FN. Cytidine deaminases: AIDing DNA demethylation? Genes Dev (2010) 24(19):2107-14. doi:10.1101/gad.1963010

97. Bransteitter R, Pham P, Scharff MD, Goodman MF. Activation-induced cytidine deaminase deaminates deoxycytidine on single-stranded DNA but requires the action of RNase. Proc Natl Acad Sci U S A (2003) 100(7):4102-7. doi:10.1073/pnas.0730835100

98. Pavri R, Gazumyan A, Jankovic M, Di Virgilio M, Klein I, Ansarah-Sobrinho $\mathrm{C}$, et al. Activation-induced cytidine deaminase targets DNA at sites of RNA polymerase II stalling by interaction with Spt5. Cell (2010) 143(1):122-33. doi:10.1016/j.cell.2010.09.017

99. Storck S, Aoufouchi S, Weill JC, Reynaud CA. AID and partners: for better and (not) for worse. Curr Opin Immunol (2011) 23(3):337-44. doi:10.1016/j.coi. 2011.02.002

100. Duke JL, Liu M, Yaari G, Khalil AM, Tomayko MM, Shlomchik MJ, et al. Multiple transcription factor binding sites predict AID targeting in non-Ig genes. J Immunol (2013) 190(8):3878-88. doi:10.4049/jimmunol.1202547

101. Kohli RM, Zhang Y. TET enzymes, TDG and the dynamics of DNA demethylation. Nature (2013) 502(7472):472-9. doi:10.1038/nature 12750

102. Huang Y, Rao A. Connections between TET proteins and aberrant DNA modification in cancer. Trends Genet (2014) 30(10):464-74. doi:10.1016/j.tig.2014. 07.005

103. Pfaffeneder T, Spada F, Wagner M, Brandmayr C, Laube SK, Eisen D, et al. Tet oxidizes thymine to 5-hydroxymethyluracil in mouse embryonic stem cell DNA. Nat Chem Biol (2014) 10(7):574-81. doi:10.1038/nchembio.1532

104. Wahlfors J, Hiltunen H, Heinonen K, Hamalainen E, Alhonen L, Janne J. Genomic hypomethylation in human chronic lymphocytic leukemia. Blood (1992) 80(8):2074-80.

105. Kulis M, Heath S, Bibikova M, Queiros AC, Navarro A, Clot G, et al. Epigenomic analysis detects widespread gene-body DNA hypomethylation in chronic lymphocytic leukemia. Nat Genet (2012) 44(11):1236-42. doi:10.1038/ng.2443

106. Fabris S, Scarciolla O, Morabito F, Cifarelli RA, Dininno C, Cutrona G, et al. Multiplex ligation-dependent probe amplification and fluorescence in situ hybridization to detect chromosomal abnormalities in chronic lymphocytic leukemia: a comparative study. Genes Chromosomes Cancer (2011) 50(9):726-34. doi:10.1002/gcc.20894

107. Chambwe N, Kormaksson M, Geng H, De S, Michor F, Johnson NA, et al. Variability in DNA methylation defines novel epigenetic subgroups of DLBCL associated with different clinical outcomes. Blood (2014) 123(11):1699-708. doi:10.1182/blood-2013-07-509885

108. Choi JH, Li Y, Guo J, Pei L, Rauch TA, Kramer RS, et al. Genome-wide DNA methylation maps in follicular lymphoma cells determined by methylationenriched bisulfite sequencing. PLoS One (2010) 5(9). doi:10.1371/journal. pone.0013020

109. Shaknovich R, De S, Michor F. Epigenetic diversity in hematopoietic neoplasms. Biochim Biophys Acta (2014) 1846(2):477-84. doi:10.1016/j.bbcan. 2014.09.003

110. Oshima M, Iwama A. Epigenetics of hematopoietic stem cell aging and disease. Int J Hematol (2014) 100(4):326-34. doi:10.1007/s12185-014-1647-2

111. Dykstra B, de Haan G. Hematopoietic stem cell aging and self-renewal. Cell Tissue Res (2008) 331(1):91-101. doi:10.1007/s00441-007-0529-9

112. Potter JD. Methyl supply, methyl metabolizing enzymes and colorectal neoplasia. J Nutr (2002) 132(8 Suppl):2410S-2S.
113. Wilson MJ, Shivapurkar N, Poirier LA. Hypomethylation of hepatic nuclear DNA in rats fed with a carcinogenic methyl-deficient diet. Biochem J (1984) 218(3):987-90.

114. Soares J, Pinto AE, Cunha CV, Andre S, Barao I, Sousa JM, et al. Global DNA hypomethylation in breast carcinoma: correlation with prognostic factors and tumor progression. Cancer (1999) 85(1):112-8. doi:10.1002/(SICI)10970142(19990101)85:1<112::AID-CNCR16>3.0.CO;2-T

115. Kim YI, Giuliano A, Hatch KD, Schneider A, Nour MA, Dallal GE, et al. Global DNA hypomethylation increases progressively in cervical dysplasia and carcinoma. Cancer (1994) 74(3):893-9. doi:10.1002/1097-0142(19940801)74: 3<893::AID-CNCR2820740316>3.0.CO;2-B

116. Shen L, Fang J, Qiu D, Zhang T, Yang J, Chen S, et al. Correlation between DNA methylation and pathological changes in human hepatocellular carcinoma. Hepatogastroenterology (1998) 45(23):1753-9.

117. Ramchandani S, Bhattacharya SK, Cervoni N, Szyf M. DNA methylation is a reversible biological signal. Proc Natl Acad Sci U S A (1999) 96(11):6107-12. doi:10.1073/pnas.96.11.6107

118. Cervoni N, Bhattacharya S, Szyf M. DNA demethylase is a processive enzyme. J Biol Chem (1999) 274(13):8363-6. doi:10.1074/jbc.274.13.8363

119. Hamm S, Just G, Lacoste N, Moitessier N, Szyf M, Mamer O. On the mechanism of demethylation of 5-methylcytosine in DNA. Bioorg Med Chem Lett (2008) 18(3):1046-9. doi:10.1016/j.bmcl.2007.12.027

120. Bhattacharya SK, Ramchandani S, Cervoni N, Szyf M. A mammalian protein with specific demethylase activity for mCpG DNA. Nature (1999) 397(6720):579-83. doi:10.1038/17533

121. Robbiani DF, Bunting S, Feldhahn N, Bothmer A, Camps J, Deroubaix S, et al. AID produces DNA double-strand breaks in non-Ig genes and mature B cell lymphomas with reciprocal chromosome translocations. Mol Cell (2009) 36(4):631-41. doi:10.1016/j.molcel.2009.11.007

122. Esteller M. Epigenetics in cancer. N Engl J Med (2008) 358(11):1148-59. doi:10.1056/NEJMra072067

123. Hoffmann MJ, Schulz WA. Causes and consequences of DNA hypomethylation in human cancer. Biochem Cell Biol (2005) 83(3):296-321. doi:10.1139/ o05-036

124. Gaudet F, Hodgson JG, Eden A, Jackson-Grusby L, Dausman J, Gray JW, et al. Induction of tumors in mice by genomic hypomethylation. Science (2003) 300(5618):489-92. doi:10.1126/science.1083558

125. Hervouet E, Lalier L, Debien E, Cheray M, Geairon A, Rogniaux H, et al. Disruption of Dnmt1/PCNA/UHRF1 interactions promotes tumorigenesis from human and mice glial cells. PLoS One (2010) 5(6):e11333. doi:10.1371/journal. pone. 0011333

126. Smit LA, Bende RJ, Aten J, Guikema JE, Aarts WM, van Noesel CJ. Expression of activation-induced cytidine deaminase is confined to B-cell nonHodgkin's lymphomas of germinal-center phenotype. Cancer Res (2003) 63(14):3894-8.

127. Greeve J, Philipsen A, Krause K, Klapper W, Heidorn K, Castle BE, et al. Expression of activation-induced cytidine deaminase in human B-cell nonHodgkin lymphomas. Blood (2003) 101(9):3574-80. doi:10.1182/blood-200208-2424

128. Gu X, Shivarov V, Strout MP. The role of activation-induced cytidine deaminase in lymphomagenesis. Curr Opin Hematol (2012) 19(4):292-8. doi:10. 1097/MOH.0b013e328353da3a

129. Pasqualucci L, Neumeister P, Goossens T, Nanjangud G, Chaganti RS, Kuppers $\mathrm{R}$, et al. Hypermutation of multiple proto-oncogenes in B-cell diffuse large-cell lymphomas. Nature (2001) 412(6844):341-6. doi:10.1038/35085588

130. Bergsagel PL, Kuehl WM. Chromosome translocations in multiple myeloma. Oncogene (2001) 20(40):5611-22. doi:10.1038/sj.onc.1204641

131. Kuppers R. Mechanisms of B-cell lymphoma pathogenesis. Nat Rev Cancer (2005) 5(4):251-62. doi:10.1038/nrc1589

132. Ramiro AR, Jankovic M, Eisenreich T, Difilippantonio S, Chen-Kiang S, Muramatsu $\mathrm{M}$, et al. AID is required for $\mathrm{c}-\mathrm{myc} / \mathrm{IgH}$ chromosome translocations in vivo. Cell (2004) 118(4):431-8. doi:10.1016/j.cell.2004.08.006

133. Kovalchuk AL, duBois W, Mushinski E, McNeil NE, Hirt C, Qi CF, et al. AID-deficient Bcl-xL transgenic mice develop delayed atypical plasma cell tumors with unusual Ig/Myc chromosomal rearrangements. J Exp Med (2007) 204(12):2989-3001. doi:10.1084/jem.20070882

134. Lohr JG, Stojanov P, Lawrence MS, Auclair D, Chapuy B, Sougnez C, et al. Discovery and prioritization of somatic mutations in diffuse large B-cell 
lymphoma (DLBCL) by whole-exome sequencing. Proc Natl Acad Sci U S A (2012) 109(10):3879-84. doi:10.1073/pnas.1121343109

135. Cattoretti G, Pasqualucci L, Ballon G, Tam W, Nandula SV, Shen Q, et al. Deregulated BCL6 expression recapitulates the pathogenesis of human diffuse large B cell lymphomas in mice. Cancer Cell (2005) 7(5):445-55. doi:10.1016/j.ccr. 2005.03.037

136. Pasqualucci L, Bhagat G, Jankovic M, Compagno M, Smith P, Muramatsu M, et al. AID is required for germinal center-derived lymphomagenesis. Nat Genet (2008) 40(1):108-12. doi:10.1038/ng.2007.35

137. Takizawa M, Tolarova H, Li Z, Dubois W, Lim S, Callen E, et al. AID expression levels determine the extent of $\mathrm{cMyc}$ oncogenic translocations and the incidence of B cell tumor development. J Exp Med (2008) 205(9):1949-57. doi:10.1084/jem.20081007

138. Chesi M, Robbiani DF, Sebag M, Chng WJ, Affer M, Tiedemann R, et al. AIDdependent activation of a MYC transgene induces multiple myeloma in a conditional mouse model of post-germinal center malignancies. Cancer Cell (2008) 13(2):167-80. doi:10.1016/j.ccr.2008.01.007

139. Okazaki IM, Hiai H, Kakazu N, Yamada S, Muramatsu M, Kinoshita K, et al. Constitutive expression of AID leads to tumorigenesis. J Exp Med (2003) 197(9):1173-81. doi:10.1084/jem.20030275

140. Komeno Y, Kitaura J, Watanabe-Okochi N, Kato N, Oki T, Nakahara F, et al. AID-induced T-lymphoma or B-leukemia/lymphoma in a mouse BMT model. Leukemia (2010) 24(5):1018-24. doi:10.1038/leu.2010.40

141. De S, Shaknovich R, Riester M, Elemento O, Geng H, Kormaksson M, et al. Aberration in DNA methylation in B-cell lymphomas has a complex origin and increases with disease severity. PLoS Genet (2013) 9(1):e1003137. doi:10.1371/journal.pgen.1003137

142. TNHLCP. A clinical evaluation of the International Lymphoma Study Group classification of non-Hodgkin's lymphoma. The non-Hodgkin's lymphoma classification project. Blood (1997) 89(11):3909-18.

Conflict of Interest Statement: The authors declare that the research was conducted in the absence of any commercial or financial relationships that could be construed as a potential conflict of interest.

Received: 07 October 2014; accepted: 02 December 2014; published online: 18 December 2014.

Citation: Dominguez PM and Shaknovich R (2014) Epigenetic function of activationinduced cytidine deaminase and its link to lymphomagenesis. Front. Immunol. 5:642. doi: $10.3389 /$ fimmu.2014.00642

This article was submitted to B Cell Biology, a section of the journal Frontiers in Immunology.

Copyright (C) 2014 Dominguez and Shaknovich. This is an open-access article distributed under the terms of the Creative Commons Attribution License (CC BY). The use, distribution or reproduction in other forums is permitted, provided the original author(s) or licensor are credited and that the original publication in this journal is cited, in accordance with accepted academic practice. No use, distribution or reproduction is permitted which does not comply with these terms. 